\title{
Evaluation of Mechanical and Durability Performance of Coir Pith Ash Blended Cement Concrete
}

\author{
Balagopal V, Viswanathan T. S* \\ Department of Structural and Geo-technical Engineering, School of Civil Engineering, Vellore Institute of Technology, Vellore, India
}

Received August 5, 2020; Revised September 22, 2020; Accepted October 19, 2020

\section{Cite This Paper in the following Citation Styles}

(a): [1] Balagopal V, Viswanathan T.S, "Evaluation of Mechanical and Durability Performance of Coir Pith Ash Blended Cement Concrete," Civil Engineering and Architecture, Vol. 8, No. 5, pp. 1028 - 1038, 2020. DOI: 10.13189/cea.2020.080529.

(b): Balagopal V, Viswanathan T.S (2020). Evaluation of Mechanical and Durability Performance of Coir Pith Ash Blended Cement Concrete. Civil Engineering and Architecture, 8(5), 1028 - 1038. DOI: 10.13189/cea.2020.080529.

Copyright $@ 2020$ by authors, all rights reserved. Authors agree that this article remains permanently open access under the terms of the Creative Commons Attribution License 4.0 International License

\begin{abstract}
India is one of the prominent producers of coconuts in the world. Along with the desired products, many undesirable by-products are also generated from the coconut and coir industry. Among the various by-products, coir pith and short coir fibres are the major ones and are obtained during the extraction of long coconut fibres. Raw coir pith was heated in a metallic vessel at $450{ }^{\circ} \mathrm{C}$ to obtain coir pith ash. In this study, the impact of the presence of $\mathrm{CPA}$ as a supplementary cementitious material, on the various mechanical and durability parameters are taken into consideration. The various parameters considered for assessing the mechanical performance include compressive strength, split tensile strength, flexural strength and Ultrasonic pulse velocity. Water absorption and resistance to sulphuric acid environments were considered to evaluate the durability of CPA blended concrete. The resistance of CPA blended concrete against sulphuric acid environment was evaluated by considering the variation in weight, water absorption and percentage loss in compressive strength. Five concrete mixes were used for the study with CPA content ranging from $0 \%$ to $20 \%$. Indian standard method of concrete mix design with water-cement ratio 0.45 was adopted. To understand the effect of change in water-cement ratio on the durability parameters of concrete, the study also considered other water-cement ratios like 0.40 and 0.50 . Results indicated that the mechanical and durability performance improves when CPA is used as supplementary cementitious material. Also, the specimens with water-cement ratio 0.40 performed better than other ratios.
\end{abstract}

Keywords Concrete, Supplementary Cementitious
Materials, Coir Pith Ash, Durability, Acid Attack

\section{Introduction}

The utilization of by-products from industrial and agricultural sectors as supplementary cementitious materials (SCMs) are gaining popularity among numerous researchers across the globe. The use of SCMs not only improve the product quality of blended concrete but also reduces the cost and adverse impacts of concrete production. The most prominent and popular SCMs include fly ash, GGBS, metakaolin, sugarcane bagasse ash, wheat straw ash rice straw ash, rice husk ash, etc. [1-7]. These materials possess pozzolanic property due to the presence of amorphous silicon dioxide which undergoes secondary reaction with lime (Calcium hydroxide) present in the concrete matrix to form cementitious materials.

Concrete was considered to be a durable material and due to this consideration, concrete constructions were common even in areas of severe industrial pollution, harmful subsoil conditions and other circumstances where usage of alternate construction materials was not feasible. However, exposure conditions can have a tremendous impact on the life of concrete members. Though the durability of concrete can be assessed by compressive strength to some extent, it may not be entirely true that a strong concrete specimen or member is always durable since damage can occur due the harsh environmental conditions [8]. As per the definition given by the ACI committee, "Durability is the ability to resist weathering 
action, chemical attack, abrasion, or any other process of deterioration" [9]. A concrete member can be considered durable if it maintains its initial characteristics when it is subjected to extremely harsh environments like acidic, chloride and sulphate environments. Deterioration occurs in concrete due to external and internal factors. The external factors include chemical attack and mechanical destruction induced by erosion, abrasion, impact and cavitation. Internal stresses caused by chemical reaction, porosity and permeability can be categorized as internal factors. Concrete is alkaline in nature and the acidic environment tends to impart neutralization reaction which reduces the alkalinity of concrete by reacting with hydration products to form calcium sulpho-aluminate (ettringite) and gypsum. These products possess low structural strength but require more space than the reagent compounds. Internal stresses are thus induced which results in the formation of cracks which eventually leads to reduction in strength [10]

The annual production of coconuts in India is nearly 11 megatonnes [11]. A spongy material known as coir pith is generated from coir processing unit which can be considered as a by-product. It is very interesting to note that coir pith constitutes $70 \%$ of the weight of coconut husk and the long fibres range only up to $30 \%$ [12]. Also, the rate of coir pith production ranges to 1.6 tonnes per 10000 coconuts [13]. The obtained coir pith is usually dumped in heaps and creates various environmental problems due to its slow degrading nature as well as the presence of phenolic compounds. Coir Pith ash (CPA) is obtained by burning dried coir pith ash at $400{ }^{\circ} \mathrm{C}$ for 4 hours. Then it was subjected to cooling for a duration of 6 hours. The obtained raw coir pith ash was sieved using 90-micron sieve. In a recent study, CPA passing through 200-micron sieve has been found to possess pozzolanic properties and the replacement of cement by CPA improved the mechanical performance of concrete [14]. However, the durability performance studies of CPA blended concrete were not carried out. Therefore, the research aims to assess the performance of binary blended cement concrete containing CPA passing through 90 microns by considering mechanical and durability parameters.

\section{Materials}

The materials used for the research included cement, fine aggregate, coarse aggregate and CPA. The cement used in the study fulfilled the requirements mentioned in IS 12269:2013 [15]. The standard consistency and specific gravity were found to be $36.75 \%$ and 3.15 respectively. Both initial and final setting time of cement were found out and the values were 77 minutes and 320 minutes respectively. Fine aggregate with used was natural river sand with a specific gravity of 2.67. The specific gravity of coarse aggregate was 2.70 . Fineness modulus and specify gravity of coarse aggregates were found to be 7.22 and 0.81 respectively. The coir pith ash (CPA) used for the study was prepared by heating coir pith at $400^{\circ} \mathrm{C}$ for 4 hours. Fig. 1 and Fig. 2 show the Coir pith and Coir pith ash respectively. The details of various chemical components of CPA are shown in table 1.

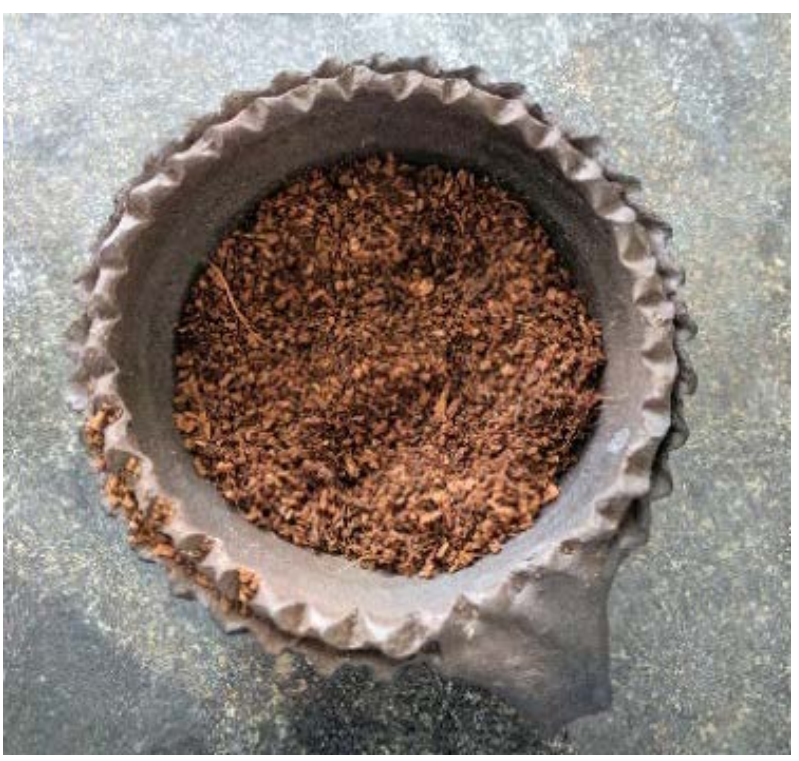

Figure 1. Coir Pith

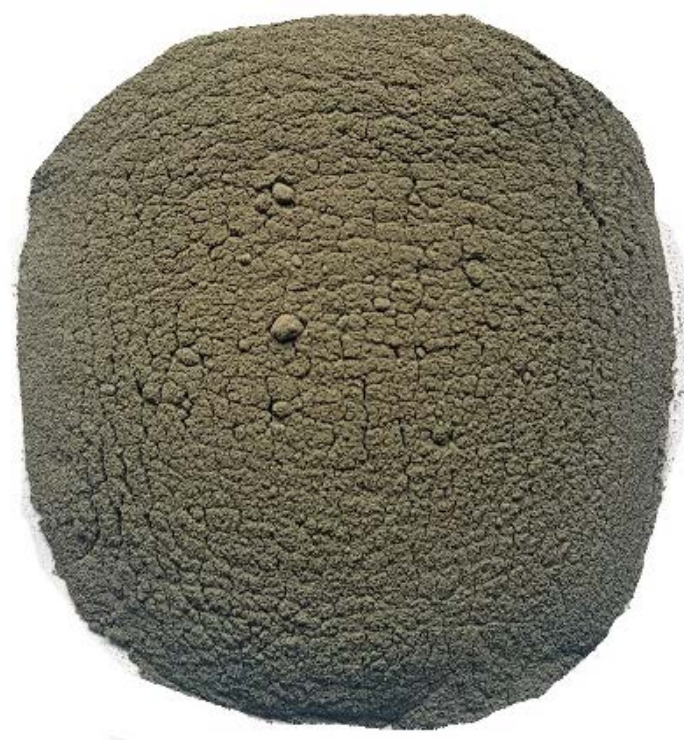

Figure 2. Coir pith ash

Table 1. Chemical Composition of OPC \& CPA

\begin{tabular}{|c|c|c|}
\hline Composition & OPC (\%) [16] & CPA (\%) \\
\hline $\mathrm{CaO}$ & $60-67$ & 14.40 \\
\hline $\mathrm{SiO}_{2}$ & $17-25$ & 46.85 \\
\hline $\mathrm{Al}_{2} \mathrm{O}_{3}$ & $3.0-8.0$ & 1.76 \\
\hline $\mathrm{Fe}_{2} \mathrm{O}_{3}$ & $0.5-6.0$ & 4.34 \\
\hline $\mathrm{MgO}$ & $0.1-4.0$ & 2.84 \\
\hline $\mathrm{SO}_{3}$ & $1.3-3.0$ & - \\
\hline $\mathrm{LOI}$ & - & 7.24 \\
\hline
\end{tabular}


Table 2. Compositions of Various Mixes

\begin{tabular}{|c|c|c|c|c|c|c|}
\hline Mix No & CPA \% & $\begin{array}{c}\text { CPA } \\
(\mathrm{Kg})\end{array}$ & $\begin{array}{c}\text { Cement } \\
(\mathrm{Kg})\end{array}$ & $\begin{array}{c}\text { Fine Aggregate } \\
(\mathrm{Kg})\end{array}$ & $\begin{array}{c}\text { Coarse Aggregate } \\
(\mathrm{Kg})\end{array}$ & $\begin{array}{c}\text { Water } \\
(\mathrm{Ltr})\end{array}$ \\
\hline CM & $0 \%$ & 0 & 438.13 & 655.72 & 1130.29 & 197.15 \\
\hline CC05 & $5 \%$ & 21.92 & 416.23 & 655.72 & 1130.29 & 197.15 \\
\hline CC10 & $10 \%$ & 43.81 & 394.32 & 655.72 & 1130.29 & 197.15 \\
\hline CC15 & $15 \%$ & 65.72 & 372.41 & 655.72 & 1130.29 & 197.15 \\
\hline CC20 & $20 \%$ & 87.63 & 350.51 & 655.72 & 1130.29 & 197.15 \\
\hline
\end{tabular}

The Indian standard method of mix design of concrete was carried out and the water-cement ratio adopted was 0.45 [16]. While carrying out durability studies, water-cement ratios of 0.40 and 0.50 were also taken into consideration to understand the effect of water-cement ratio on durability performance. The cement was replaced by CPA up to $20 \%$.

The mix proportions are denoted by the following representations

CM - 0\% CPA \& 100\% Cement.

CC05 - 5 \% CPA \& 95\% Cement

CC10 - $10 \%$ CPA \& 90\% Cement

CC15 - $15 \%$ CPA \& 85\% Cement

CC20 - $20 \%$ CPA \& 80\% Cement

Table 2 shows the composition of various mixes used for the research.

\section{Methods}

\subsection{Compressive Strength Test}

Cube specimens of $100 \mathrm{~mm}$ size were cast as per IS $516: 1959$ [17]. The specimens were then placed at room temperature of $27 \pm 5{ }^{\circ} \mathrm{C}$ for 24 hours. The compressive strength test using the compression testing machine was carried out at various curing ages of 7, 28, 56 and 90 days. The capacity of the machine was $2000 \mathrm{kN}$ and a pace rate adopted was $2.3 \mathrm{kN} / \mathrm{s}$

\subsection{Split Tensile Strength Test}

To find the split tensile strength, cylindrical concrete specimens of $100 \mathrm{~mm}$ diameter and $200 \mathrm{~mm}$ height were tested at 7, 28 and 90 days as per IS 5816-1999 [18]. Water curing method was adopted.

\subsection{Flexural Strength Test}

Flexural strength denotes the resistance against bending and was found out by conducting flexural strength test as per IS 516:1959 [17]. The load was applied until failure to concrete beam specimens of dimension $100 \times 100$ x 500 $\mathrm{mm}$ and the peak loads were noted. Three-point loading condition was used and the span length of the specimens was $500 \mathrm{~mm}$.

\subsection{Ultra Sonic Pulse Velocity Test}

There are wide variety of non-destructive testing (NDT) methods which aim to test the specimens without destructing it. Ultra-sonic pulse velocity (UPV) method is one of the prominent NDT methods and is carried out mainly to assess the uniformity and relative quality of existing structures and specimens. The test was carried out with reference to IS 13311 (Part 1): 1992 [19]. The tests were conducted on day 7, 28, 56 and 90 after casting of specimens. IS 13311 (Part 1): 1992 classifies concrete based on the value of UPV and is shown in table 3 . Various parameters of concrete quality like uniformity, absence of cracks, honeycombing, and segregation and other internal flaws in a particular specimen may be assessed by finding its UPV and comparing it with the specifications given in Table 3.

Table 3. Grading of Concrete based on UPV

\begin{tabular}{|c|c|}
\hline PULSE VELOCITY & CONCRETE QUALITY GRADING \\
\hline Above $4.5 \mathrm{Km} / \mathrm{S}$ & Excellent \\
\hline $3.5-4.5 \mathrm{Km} / \mathrm{S}$ & Good \\
\hline $3.0-3.5 \mathrm{Km} / \mathrm{S}$ & Medium \\
\hline Below $3.0 \mathrm{Km} / \mathrm{S}$ & Doubtful \\
\hline
\end{tabular}

\subsection{Water Absorption Test}

Water absorption at 28 days and 90 days were determined as per American Society for Testing and Materials [20]. The concrete cubes of $100 \mathrm{~mm}$ were the specimens. After providing curing for the required number of curing days, the specimens were kept in an electric oven for 3 days at $60{ }^{\circ} \mathrm{C}$ and then allowed to cool to normal room temperature for 24 hours. The weight $\mathrm{W}_{1}$ was then taken. After that, the cubes were submerged in water in such a way that $50 \mathrm{~mm}$ water was maintained above the cubes. After a duration of 48 hours, the specimens were taken out from the water and placed on a dry cloth for 1 minute so that the water was allowed to drain. The weight of the specimen was noted immediately after that $\left(\mathrm{W}_{2}\right)$. Water absorption was then calculated and was expressed in percentage.

$$
\text { Water Absorption }=((\mathrm{W} 2-\mathrm{W} 1) / \mathrm{W} 1) \times 100
$$

The water absorption of CPA blended concrete was compared with those of control specimens to analyze the 
impact of CPA addition to concrete.

\subsection{Acid Attack Test}

Exposure to acidic environments leads to degradation of concrete. To study the effects of the acid attack, CPA blended concrete specimens were given exposure to the sulphuric acid environment and the test was carried out as per American Society for Testing and Materials [21]. Sulphuric acid of $5 \%$ by weight of water was taken as the medium and the specimens were submerged in it. The concentration of the medium was maintained by replacing at day 1 , day 3 and then at every 7 days. Tests for water absorption, compressive strength and loss in weight were carried out on the specimens subjected to acid attack.

\subsubsection{Resistance Against Water Absorption}

The variation in the porosity of acid attacked specimens were evaluated using the water absorption test. The test was conducted on acid attacked specimens immersed in dilute sulphuric acid after 28,60 and 90 days of immersion as per American Society for Testing and Materials [21].

\subsubsection{Variation in weight of Acid Attacked Specimens}

The change in weight of the specimens immersed in dilute sulphuric acid was noted at 28, 60 and 90 days of immersion. The specimens are then kept at room temperature for a span of 24 hours and then subjected to oven drying for 3 days at $60{ }^{\circ} \mathrm{C}$. After that, the specimens were taken out of the oven and allowed to cool for 24 hours. After that, the weight was noted. The change in weight was expressed in terms of the initial oven-dried weight taken before immersion in acid solution.

\subsubsection{Variation in Compressive strength}

The variation in compressive strength was checked at 28, 60 and 90 days of immersion in dilute sulphuric acid as per American Society for Testing and Materials [22]. The obtained compressive strength was compared with normal concrete specimens which are not subjected to acid attack and water cured for 28 days after casting. The reduction in compressive strength is expressed in percentage. The variation in the dimension of the specimens after acid exposure were not considered while calculating the compressive strength

\subsection{Microstructural Analysis of CPA Blended Concrete by SEM}

Scanning electron microscope (SEM) was used to study the microstructural properties of CPA blended cement concrete specimens. The instrument used was ZEISS EVO18 and it uses electron beams to generate the enlarged images of the internal structure of sample materials. The samples were of approximate size $5 \mathrm{~mm} \mathrm{X}$ $5 \mathrm{~mm} \mathrm{X} 5 \mathrm{~mm}$ and were taken from specimens subjected to compression test carried out as per IS 516: 1959 after providing 90 days of curing. Various parameters like morphology, pore distribution and presence of hydration products were studied

\section{Results and Discussions}

\subsection{Compressive Strength of CPABlended Concrete}

The compressive strength increased with curing period. Table 4 shows the compressive strength of various mixes at different curing periods. The strength of all mixes increased with increase in curing periods. CC05 mix showed better performance than CM at all curing periods. At 28 days of curing, the strength of CM and CC05 were $31.97 \mathrm{KN}$ and $33.03 \mathrm{KN}$ respectively. At a curing period of 90 days, the compressive strength values of CM, CC05 and CC10 were $34.66 \mathrm{KN}, 37.98 \mathrm{KN}$ and $34.70 \mathrm{KN}$ respectively. Thus the strength of CC10 was observed to be slightly higher than that of CM. For CC05 and CC10 mixes, the effect of the pozzolanic reaction was well observed at 90 days of curing and it contributed to the better mechanical performance. As the percentage of CPA content increased beyond 5\%, the compressive strength decreased. The decrease in strength can be attributed to a drop in cement content and a slower rate of pozzolanic reaction. The above results confirm the application and ability of the CPA to be used as a cement replacing material. However, the performance of CPA blended concrete was seemed to be lesser than that of concretes blended with other pozzolanic materials derived from agricultural by-products like sugarcane bagasse ash (SBA) and rice husk ash (RHA). From previous researches, the optimum replacement dosage of both SBA and RHA was found to be 20\%. [2, 23-26]. Also, the performance of the CPA was found to be better than that of previous researches [14, 27-28].

Table 4. Compressive Strength of CPA blended concrete specimens

\begin{tabular}{|c|c|c|c|c|}
\hline \multirow{2}{*}{ Mix } & \multicolumn{4}{|c|}{ Compressive Strength $(\mathrm{MPa})$} \\
\cline { 2 - 5 } & $7^{\text {th }}$ Day & $28^{\text {th }}$ Day & $56^{\text {th }}$ Day & $90^{\text {th }}$ Day \\
\hline CM & 29.11 & 31.97 & 33.62 & 34.66 \\
\hline CC05 & 29.43 & 33.03 & 35.81 & 37.98 \\
\hline CC10 & 26.85 & 29.44 & 33.21 & 34.70 \\
\hline CC15 & 22.45 & 26.71 & 27.07 & 27.96 \\
\hline CC20 & 15.73 & 16.98 & 20.06 & 21.13 \\
\hline
\end{tabular}

\subsection{Split Tensile Strength of CPAB Blended Concrete}

Similar to compressive strength, CC05 mix showed improved strength than $\mathrm{CM}$ at all curing periods. At 28 days of curing, the split tensile strength of $\mathrm{CM}$ and $\mathrm{CC} 05$ were $2.53 \mathrm{KN}$ and $2.59 \mathrm{KN}$ respectively. Increase in CPA content beyond $5 \%$ resulted in lowering of split tensile strength. Also, CC10 mix possessed higher strength than 
$\mathrm{CM}$ at 90 days of curing. The split tensile strength of CM, CC05 and CC10 at 90 days were $2.75 \mathrm{KN}, 3.05 \mathrm{KN}$ and $2.80 \mathrm{KN}$ respectively. The results of split tensile strength tests of CPA blended concrete specimens are shown in Table 5.

Table 5. Split tensile strength of CPA blended concrete specimens

\begin{tabular}{|c|c|c|}
\hline \multirow{2}{*}{ MIX } & \multicolumn{2}{|c|}{ Split Tensile Strength (MPa) } \\
\cline { 2 - 3 } & $28^{\text {th }}$ Day & $90^{\text {th }}$ Day \\
\hline CM & 2.53 & 2.75 \\
\hline CC05 & 2.59 & 3.05 \\
\hline CC10 & 2.43 & 2.80 \\
\hline CC15 & 2.24 & 2.37 \\
\hline CC20 & 1.99 & 2.19 \\
\hline
\end{tabular}

\subsection{Flexural Strength of CPA Blended Concrete}

At 28 days of curing, the best resistance against flexure was offered by CC05 mix. However, when the CPA content increased beyond 5\%, the strength got reduced. The strength of CM, CC05 and CC20 at 28 days of curing were $7.61 \mathrm{KN}, 7.81 \mathrm{KN}$ and 4.93 respectively. When compared with $\mathrm{CM}$, at $20 \%$ replacement, the strength reduced by $35 \%$. The flexural strength test results are shown in Table 6

Table 6. Flexural strength of CPA blended concrete specimens

\begin{tabular}{|c|c|}
\hline \multirow{2}{*}{ Mix } & Flexural Strength (MPa) \\
\cline { 2 - 2 } & $28^{\text {th }}$ Day \\
\hline CM & 7.61 \\
\hline CC05 & 7.81 \\
\hline CC10 & 7.52 \\
\hline CC15 & 6.01 \\
\hline CC20 & 4.93 \\
\hline
\end{tabular}

\subsection{Ultra Sonic Pulse Velocity Test on CPABlended Concrete}

Table 7 shows the UPV test results and the UPV tests on specimens containing CPA showed that $\mathrm{CM}$ and $\mathrm{CC} 05$ specimens showed excellent quality at all curing periods. At 28 days, 56 days, and 90 days, the UPV of CC05 specimens were more than that of CM which shows the better quality of CC05 over CM. Increased pozzolanic reactivity of CPA due to the reduction in particle size could lead to the densification of the concrete matrix by forming more CSH gels. During the initial days, the filler effect could also increase the UPV. CC10 and CC15 specimens showed excellent quality at 28,56 and 90 days. CC20 specimens showed excellent quality on 56 and 90 days of curing.
Table 7. UPV of CPA blended concrete at various curing periods

\begin{tabular}{|c|c|c|c|c|c|}
\hline \multirow{2}{*}{$\begin{array}{c}\text { Days } \\
\text { of } \\
\text { Curing }\end{array}$} & \multicolumn{5}{|c|}{ UPV (m/s) } \\
\cline { 2 - 6 } 7 Days & 4660 & 4568 & 4298 & 4051 & 3874 \\
\hline $\begin{array}{c}28 \\
\text { Days }\end{array}$ & 4968 & 4971 & 4824 & 4618 & 4434 \\
\hline $\begin{array}{c}56 \\
\text { Days }\end{array}$ & 5027 & 5147 & 5006 & 4872 & 4758 \\
\hline $\begin{array}{c}90 \\
\text { Days }\end{array}$ & 5141 & 5324 & 5150 & 5012 & 4933 \\
\hline
\end{tabular}

\subsection{Water Absorption of CPABlended Concrete}

Water absorption of oven-dried samples were calculated after immersing the specimens in water for 48 hours. The results obtained after the test are shown in Fig. 3 and Fig. 4. At 28 days, for all the water-cement ratios, the least water absorption was shown by the specimens having 5\% CPA. However, the absorption of specimens with 10\% CPA was found to be less than that of the control mix. The specimens with 15\% and 20\% CPA showed higher absorption than the control mix. At 90 days, the specimens showed a slightly different trend. The water absorption decreased till the percentage replacement increased up to $10 \%$. After that, the values seemed to be increasing. When compared with the control mix, the performance of specimens with 15\% CPA was better. The initial decrease in the water absorption indicates the reduction in the porosity and this can be attributed to change in microstructure due to pozzolanic action of CPA and filling of voids. However, when CPA content increased beyond a particular level, the reduced performance, especially at initial curing days could be due to slow rate of hydration of ash, the low pozzolanic activity of ash, and aggregation of particles.

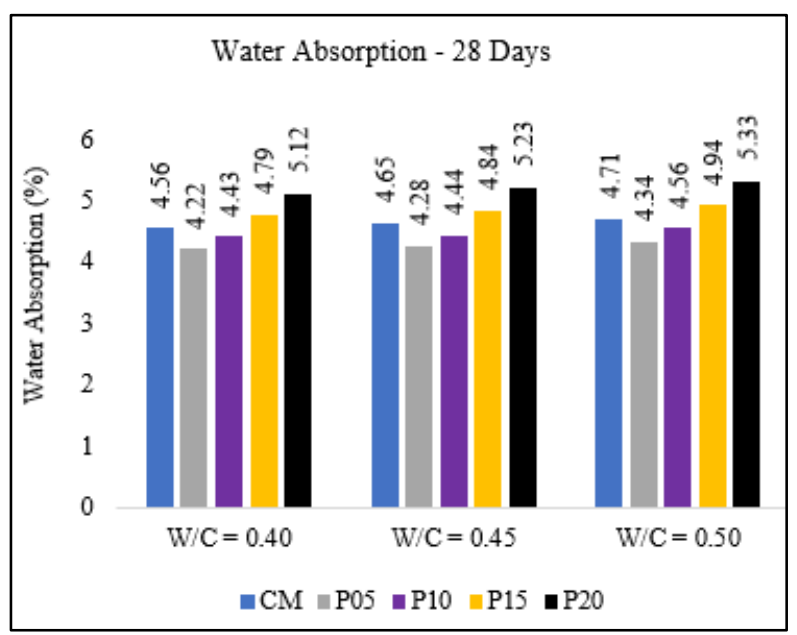

Figure 3. Variation in Water Absorption (\%) at 28 days 


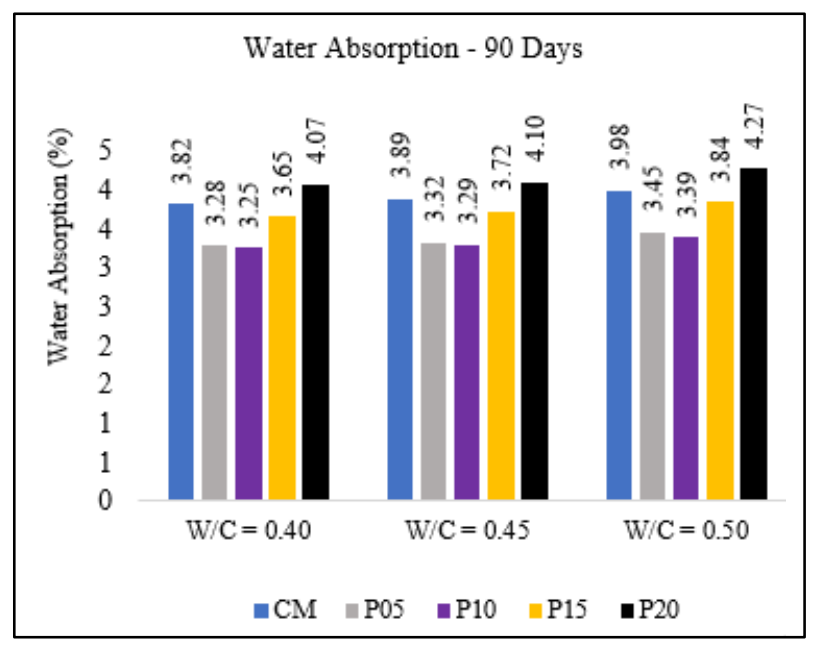

Figure 4. Variation in Water Absorption (\%) at 90 days

\subsection{Resistance of CPA Concrete Against Acid Environments}

\subsubsection{Variation in Compressive strength}

The compressive strength tests of specimens subjected to acidic environments were carried out at 28, 60 and 90 days of immersion and the results obtained were compared with compressive strength of those 28 days water cured specimens which are not exposed to the acidic environment. The loss in compressive strength was expressed in percentage and are shown in Fig. 5, Fig. 6, and Fig. 7. Different water-cement ratios, $0.40,0.45$ and 0.50 were considered. In all cases, for all the mixes, the percentage reduction in strength went on increasing with the increase in exposure duration to sulphuric acid. In water-cement ratio 0.40 , the maximum strength reduction was observed for CC20 mix and values at 28 days, 60 days and 90 days were $23.16 \%, 48.70 \%$ and $60.5 \%$, respectively. At 60 days, and 90 days, the minimum strength reduction was seen in the case of CC05 mix. However, at 28 days, CC10 mix showed better performance than the rest of the mixes.

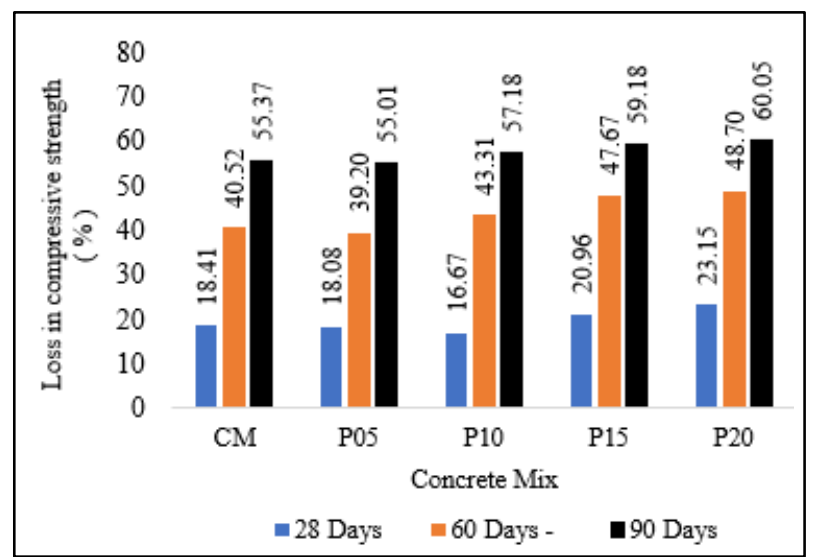

Figure 5. Compressive Strength loss (\%) of Acid Attacked concrete specimens with w/c 0.40
At 28 days of acid exposure, for water-cement ratio 0.45, the best performance was shown by CC10 mix and the value was 20.79\%. At 60 days and 90 days, CC05 mix was found to be superior to other mixes. The maximum strength reduction was shown by CC20 mix irrespective of exposure durations. The maximum values obtained for CC20 mix at 28 days, 60 days and 90 days were $23.93 \%$, $50.68 \%$ and $59.65 \%$ respectively.

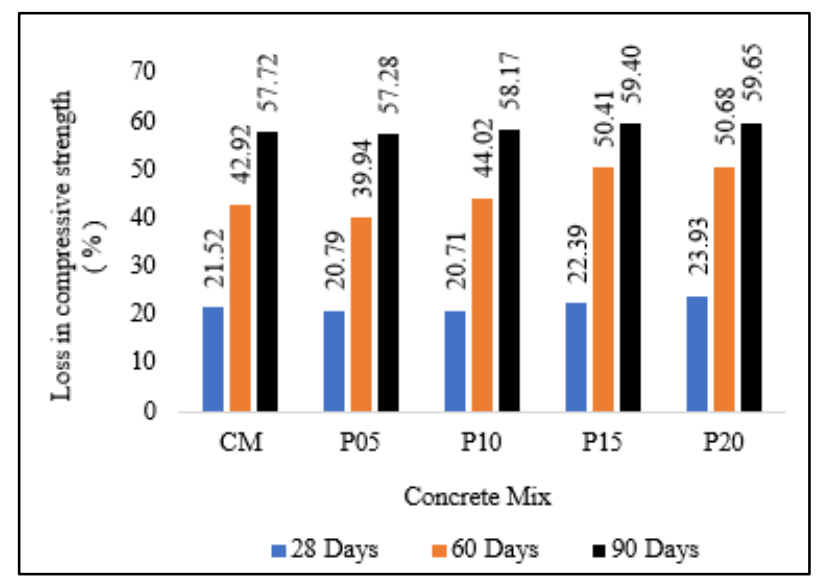

Figure 6. Compressive Strength loss (\%) of Acid Attacked concrete specimens with w/c 0.45

In water-cement ratio 0.50 , considering the strength loss, the best and worst performances were shown by CC05 and CC20 mixes respectively, at all exposure durations. In general, considering all the water-cement ratios and exposure durations, it could be inferred that the percentage reduction in compressive strength decreased up to a certain percentage of CPA addition. Increasing CPA content beyond a particular level resulted in an increase of percentage reduction. The enhanced performance during CPA addition was due to reduction in $\mathrm{C}_{3} \mathrm{~A}$ in the blended cement concrete and the pozzolanic action of CPA which depleted the $\mathrm{Ca}(\mathrm{OH})_{2}$ content. In addition to this, the filler effect caused by CPA addition reduced the permeability which in turn decreased the acid ingress which resulted in better strength of concrete. Higher percentages of CPA reduced the performance against acid attack due to reduction in cement content which reduced the Ca $(\mathrm{OH})_{2}$ content in the matrix which was supposed to react with $\mathrm{SiO}_{2}$ present in CPA. Also, from previous studies, CPA showed a slower rate of pozzolanic reaction [14]. In addition to all these factors, increasing the percentage of CPA beyond a level caused its aggregation and increased the permeability of the matrix which aided the ingress of more acid to the interior sections of the specimens. Fig. 8(a), Fig. 8(b) and Fig. 8(c) show the acid attacked specimens at 28 days with $0 \%, 10 \%$ and $20 \%$ CPA respectively. 


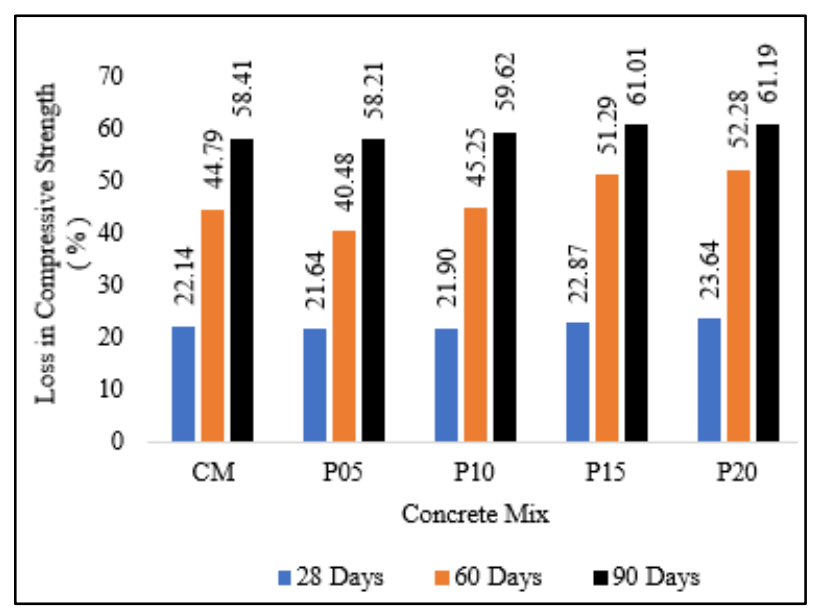

Figure 7. Compressive Strength loss (\%) of Acid Attacked concrete specimens with w/c 0.50

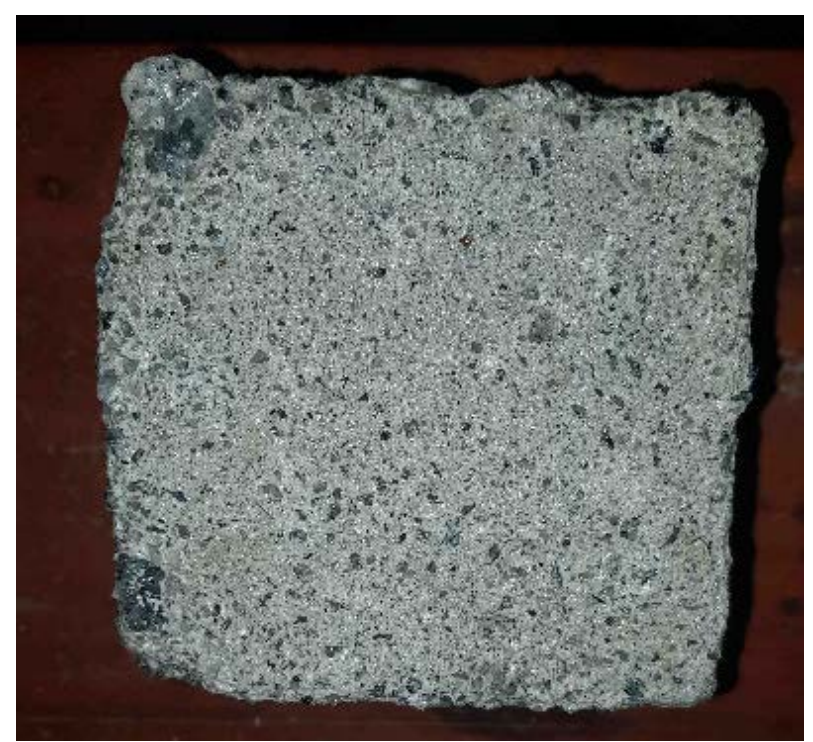

Figure 8 (a). The Acid Attacked Specimens at 28 days with $0 \%$ CPA

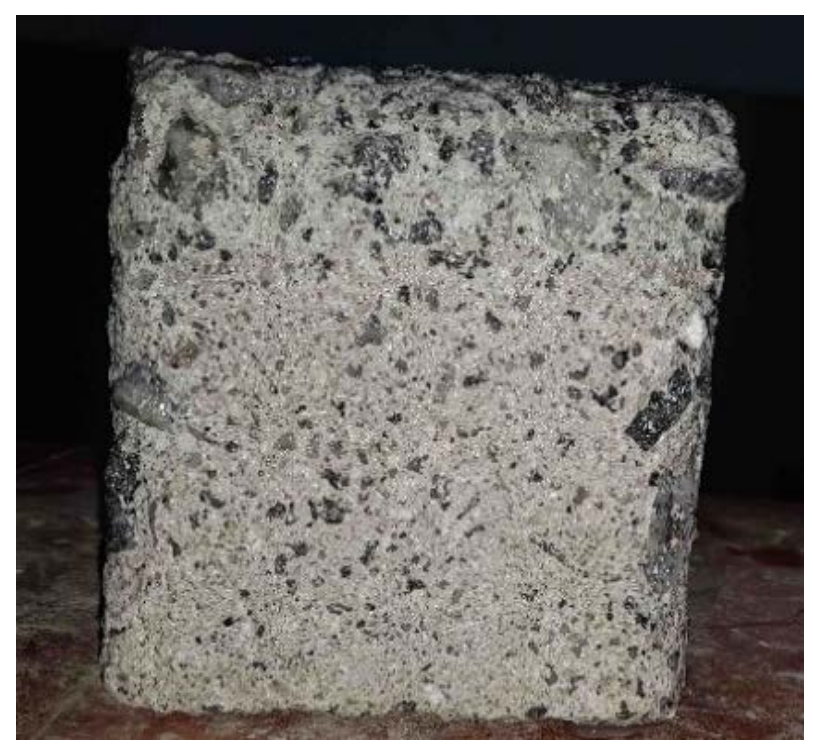

Figure 8 (b). The Acid Attacked Specimens at 28 days with 10\% CPA

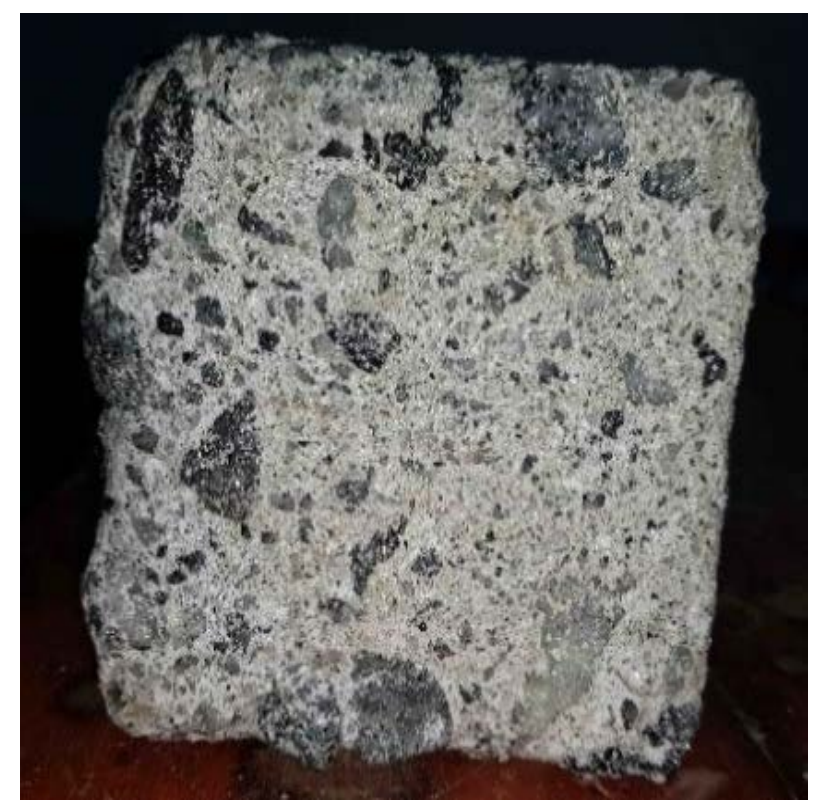

Figure 8(c). The Acid Attacked Specimens at 28 days with 20\% CPA

\subsubsection{Resistance Against Water Absorption}

Increase in the exposure duration resulted in the increase in water absorption of specimens. Fig. 9, Fig. 10 and Fig. 11 shows the water absorption of acid attacked specimens with water-cement ratio $0.40,0.45$ and 0.50 respectively. Similar trends were observed in case of concrete specimens with water-cement ratio 0.45 and 0.50 , at all exposure periods to sulfuric acid environments. The water absorption tend to decrease up to 5\% replacement and increased beyond that percentage. The same trend was observed for the water-cement ratio of 0.40 at 28 days and 60 days of acidic exposure. However, at 90 days, the water absorption decreased beyond $5 \%$ up to $10 \%$ and started to increase beyond $10 \%$. The better performance of CC05 and CC10 mixes can be attributed to the combined effect of pozzolanic reaction and filler effect of CPA. The concrete mix will have a comparatively denser matrix which reduces the chemical ingress

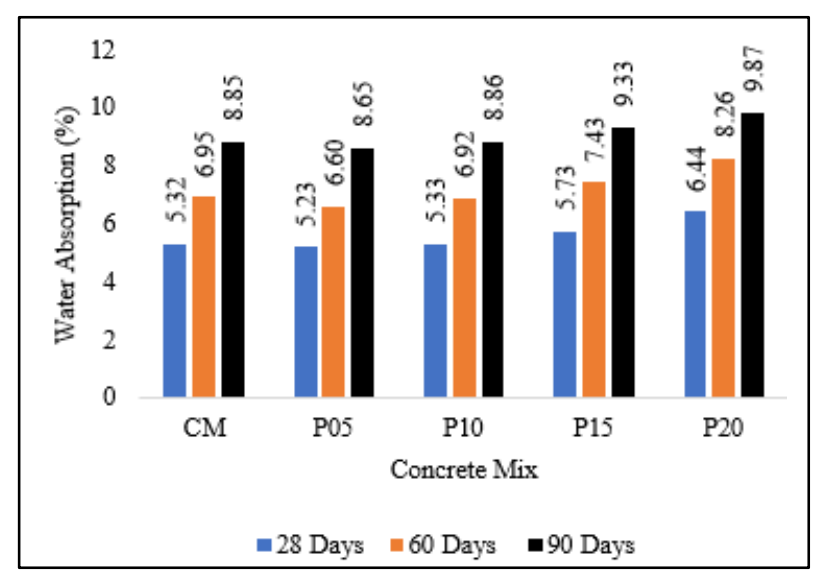

Figure 9. Water absorption of specimens with w/c 0.40 exposed to Acid Attack 


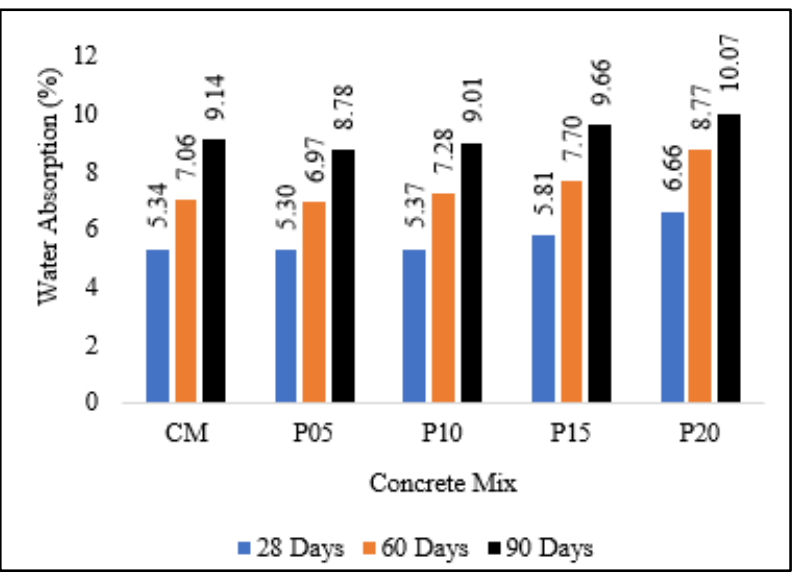

Figure 10. Water absorption of specimens with w/c 0.45 exposed to Acid Attack

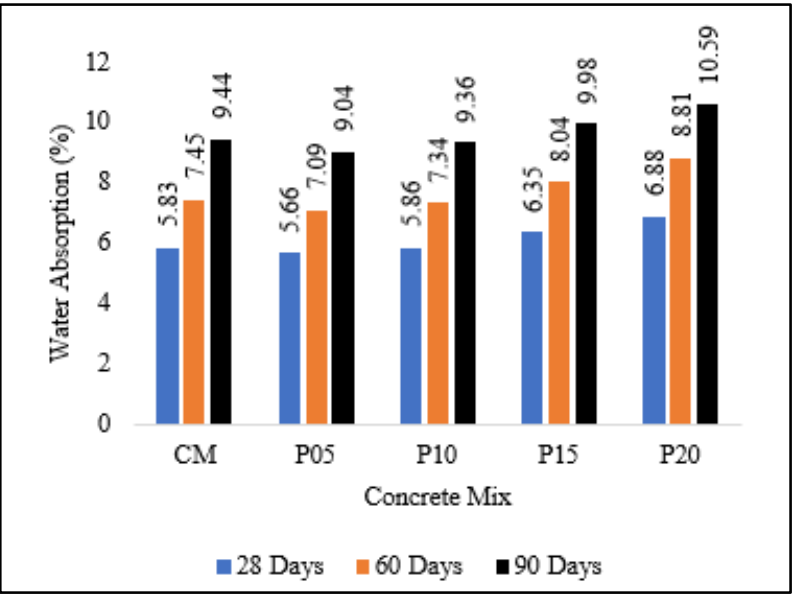

Figure 11. Water absorption of specimens with w/c 0.50 exposed to Acid Attack

\subsubsection{Variation in weight of Acid Attacked Specimens}

The variation in weight of specimens subjected to acid attack was calculated at 28, 60 and 90 days. The variation in weight was calculated by comparing the weights of non-acid attacked specimens at 28 days of water curing with those of acid attacked specimens. The loss in weight was calculated and expressed in percentage. The variation in weight loss is shown in Fig. 12, Fig. 13 and Fig. 14.

For all water-cement ratios, at 28 days of immersion, the least weight loss was observed for CC05 mix and for all other replacement percentages, the weight loss was found to be more than that of control mix. This could be due to the pozzolanic reaction of CPA which produces additional C-S-H gel by reacting with calcium hydroxide, that improves the quality of concrete. Similarly, at 60 days of immersion, for water-cement ratio 0.40, CC05 mix showed least weight loss. But for water-cement ratios 0.45 and 0.50 , the best performance was shown by CC10 mix. At 90 days, just like at 28 days, CC05 showed the best values compared to all other mixes. The reduction in performance at 90 days when compared to 60 days was due to conversion of $\mathrm{Ca}(\mathrm{OH})_{2}$ to gypsum which gets leached away. Since CPA cannot react in the absence of calcium hydroxide, the pozzolanic action ceases.

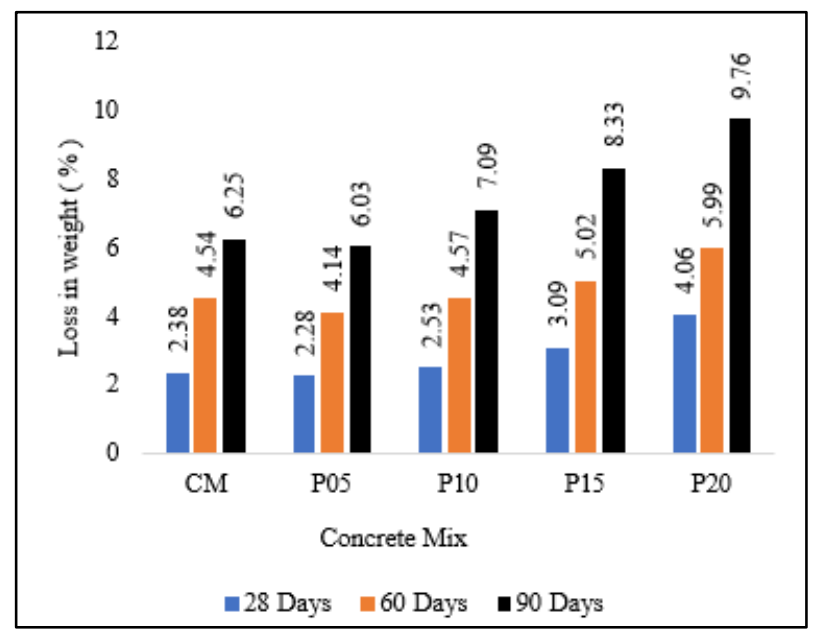

Figure 12. Weight loss (\%) of specimens with w/c 0.40 exposed to Acid Attack

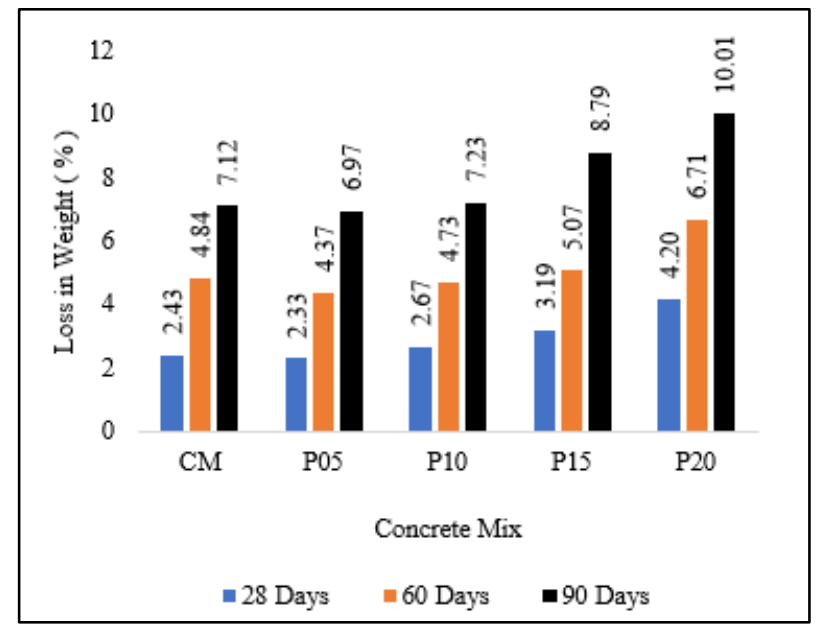

Figure 13. Weight loss (\%) of specimens with w/c 0.45 exposed to Acid Attack

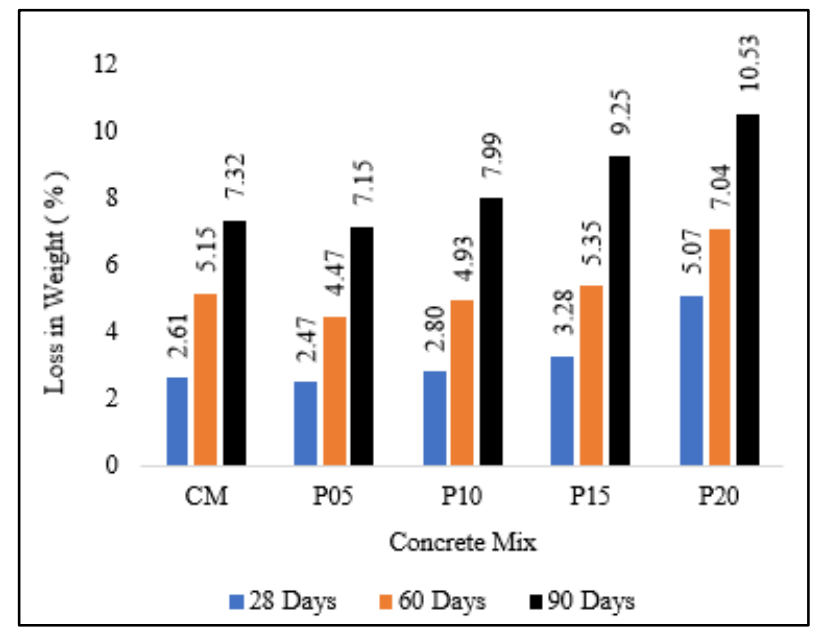

Figure 14. Weight loss (\%) of specimens with w/c 0.50 exposed to Acid Attack 


\subsection{Microstructural Analysis of CPABlended Concrete by SEM}

In the study, the various mixes taken into consideration were CM, CC05, CC10 and CC15. All samples were taken after providing 90 days of curing period. The SEM image of control mix concrete is shown in Fig. 15 and it shows the presence of dense C-S-H phase and plate-like Ca $(\mathrm{OH})_{2}$ phase along with a considerable amount of void spaces. $\mathrm{C}-\mathrm{S}-\mathrm{H}$ phase is one of the most prominent components that influence the microstructural and mechanical characteristics of concrete.

The microstructural details of CC05 is shown in Fig. 16. Comparing the SEM images of CM and CC05 reveals that, CC05 mix possess comparatively a denser microstructure than CM. The number of pores also got reduced to a greater extend. The presence of $\mathrm{Ca}(\mathrm{OH})_{2}$ in $\mathrm{CC} 05$ was not as much as in case of CM. These details proved the pozzolanic reaction of CPA which eliminated the calcium hydroxide content in the matrix. The C-S-H phase formed from $\mathrm{Ca}$ $(\mathrm{OH})_{2}$ occupied the empty void spaces and led to the formation of a denser microstructure. This in turn resulted in the superior mechanical and durability performance of CC05.

Figures 17 \& 18 show the SEM images of CC10 and CC15 respectively. As far as the compactness of microstructure and voids are concerned, CC10 and CM mixes possess similar microstructural characteristics. Increase in CPA content beyond $10 \%$ led to the formation of less compacted microstructure with an increased number of pores. Even though, the amount of $\mathrm{Ca}(\mathrm{OH})_{2}$ is lesser due to pozzolanic reaction, the voids are more due to reduced formation of hydration products as cement content got decreased.

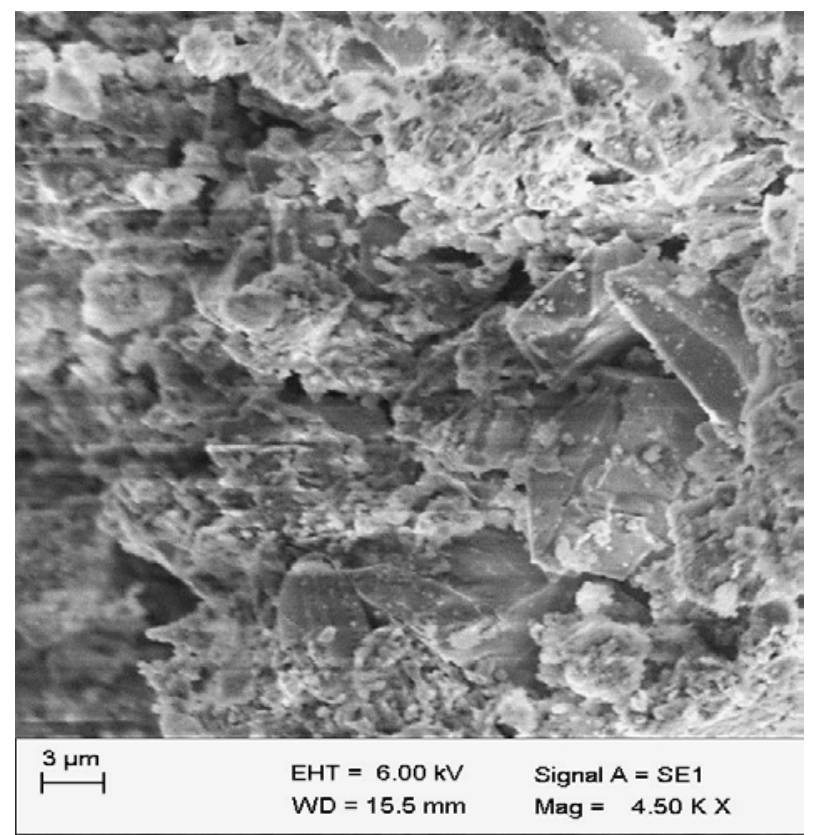

Figure 15. SEM image of CM at 90 days $(\mathrm{w} / \mathrm{c}=0.45)$

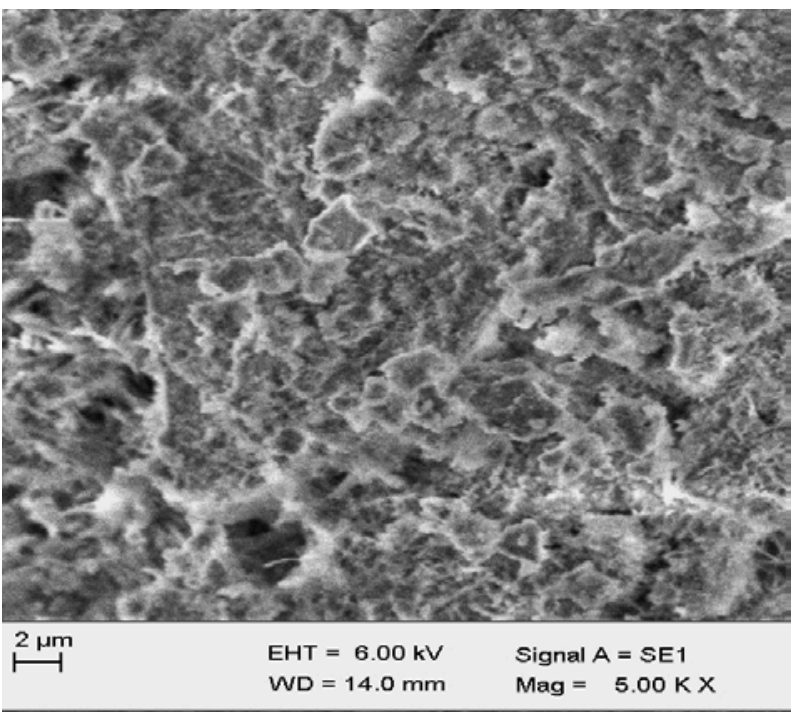

Figure 16. SEM image of CC05 at 90 days $(\mathrm{w} / \mathrm{c}=0.45)$

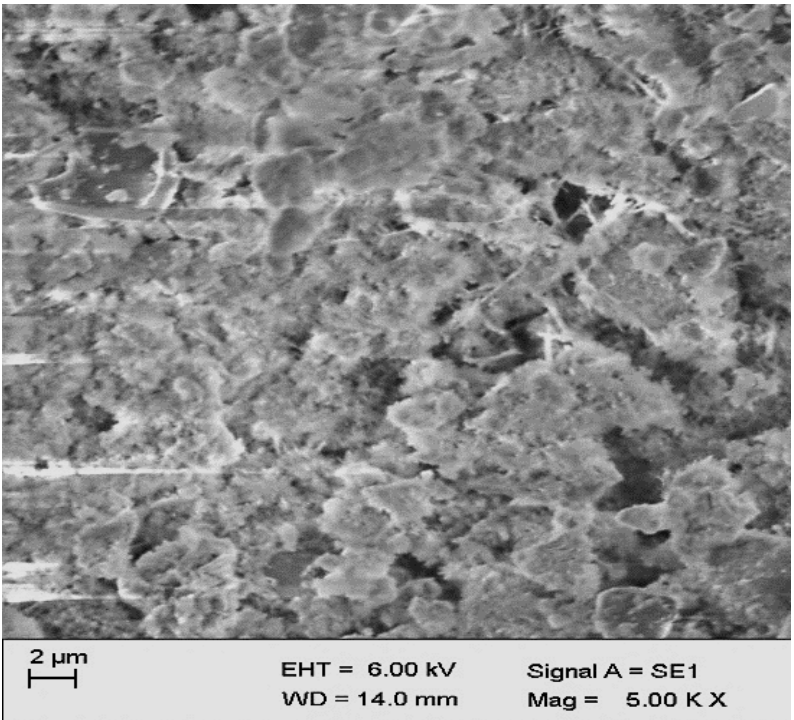

Figure 17. SEM image of CC10 at 90 days $(\mathrm{w} / \mathrm{c}=0.45)$

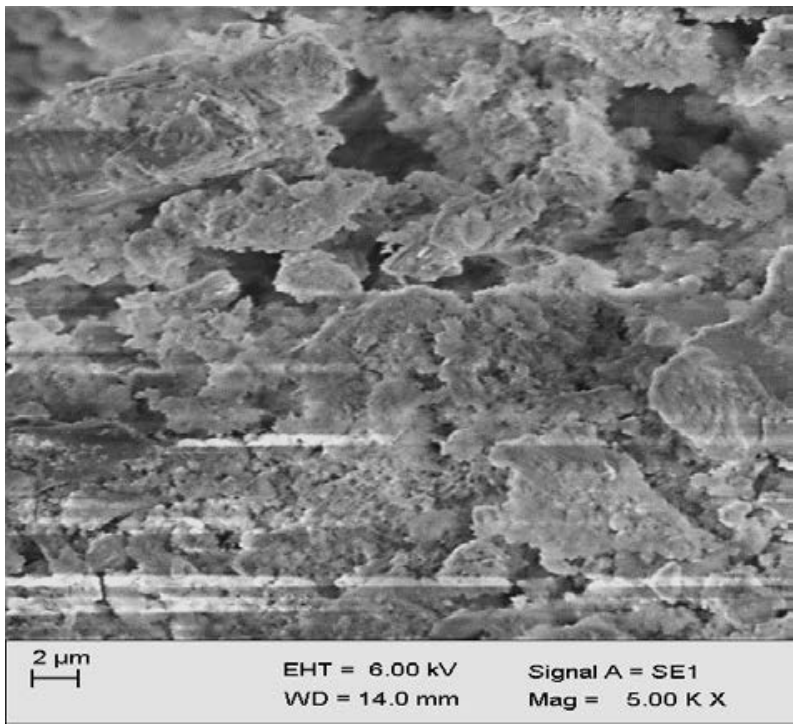

Figure 18. SEM image of CC15 at 90 days $(\mathrm{w} / \mathrm{c}=0.45)$ 


\section{Conclusion}

The purpose of the research was to check the performance of CPA as cement replacing material and to understand the mechanical and durability properties of CPA blended cement concrete. From the various tests conducted, the following conclusions were drawn.

- CC05 mix showed the best mechanical performance irrespective of the curing periods. Also, at 90 days of curing, CC10 mix performed better than CM.

- UPV values of all specimens were more than $3.5 \mathrm{~km} / \mathrm{s}$ which showed the good quality of specimens. Similarly, at 56 and 90 days of curing, UPV of all specimens were more than $4.5 \mathrm{~km} / \mathrm{s}$ which showed the excellent quality of the specimens.

- The performance of CPA blended concrete against water absorption improved with the addition of CPA up to a certain percentage. The optimum percentage of CPA replacement at 90 days was found to be $15 \%$.

- The water absorption and weight loss specimens subjected to acid attack were found to decrease with the addition of CPA up to 5\% replacement levels, at all curing periods, irrespective of the water-cement ratio.

- For water-cement ratios 0.40 and 0.45 , at 28 days of acid exposure, the percentage reduction in compressive strength was observed to decrease up to $10 \%$ CPA replacements. In all other cases, the best performance was shown by the specimens containing 5\% CPA

- Also, the specimens with water-cement ratio 0.40 performed better than water-cement ratios 0.45 and 0.50 .

- The internal microstructural details of CPA blended specimens were studied using a scanning electron microscope. At 5\% replacement level, the microstructure was found to be denser than at $0 \%$ replacement. Also, the microstructure observed at $10 \%$ replacement levels was almost similar to that at $0 \%$ replacement. The microstructure analysis supports the better the performance shown by CPA blended concrete with CPA levels up to $10 \%$.

\section{REFERENCES}

[1] Khan, R., Jabbar, A., Ahmad, I., Khan, W., Khan, A. N., \& Mirza, J. (2012). Reduction in environmental problems using rice-husk ash in concrete. Construction and Building Materials, 30, 360-365. DOI: 10.1016/j.conbuildmat.2011.1 1.028

[2] Madandoust, R., Ranjbar, M. M., Moghadam, H. A., \& Mousavi, S. Y. (2011). Mechanical properties and durability assessment of rice husk ash concrete. Biosystems engineering, 110(2), 144-152. DOI: 10.1016/j.biosystemsen g.2011.07.009
[3] Bhanumathidas, N., \& Mehta, P. K. (2001). Concrete mixtures made with ternary blended cements containing fly ash and rice-husk ash. Special Publication, 199, 379-392. DOI: $10.14359 / 10505$

[4] Oner, A., \& Akyuz, S. (2007). An experimental study on optimum usage of GGBS for the compressive strength of concrete. Cement and Concrete Composites, 29(6), 505-514, DOI: 10.1016/j.cemconcomp.2007.01.001

[5] Ding, J. T., \& Li, Z. (2002). Effects of metakaolin and silica fume on properties of concrete. Materials Journal, 99(4), 393-398. DOI: $10.14359 / 12222$

[6] Cordeiro, G. C., Toledo Filho, R. D., Tavares, L. M., \& Fairbairn, E. M. R. (2008). Pozzolanic activity and filler effect of sugar cane bagasse ash in Portland cement and lime mortars. Cement and Concrete composites, 30(5), 410-418, DOI: 10.1016/j.cemconcomp.2008.01.001.

[7] Biricik, H., Aköz, F., Lhan Berktay, I., \& Tulgar, A. N. (1999). Study of pozzolanic properties of wheat straw ash. Cement and concrete research, 29(5), 637-643, DOI: 10.1016/S0008-8846(98)00249-X.

[8] Ogork, E. N., Aboshio, A., \& Balami, D. A. (2010). Durability assessment of concrete made with rice husk ash as admixture. Journal of Engineering and Technology (JET), Faculty of Engineering, Bayero University, Kano, Nigeria, 5(1), 90-98.

[9] ACI Committee 201: Guide to durable concrete, American Concrete Institute, Report of ACI Committee, Detroit, 2001

[10] Monteny, J., et al. "Chemical and microbiological tests to simulate sulfuric acid corrosion of polymer-modified concrete." Cement and Concrete Research 31.9 (2001): 1359-1365, DOI: 10.1016/S0008-8846(01)00565-8

[11] FAO, FAO Statistical Yearbook 2014, Food and Agriculture Organization of the United Nations, 2014

[12] Fontenele, R. E. S. (2005). Coconut culture in Brazil: current market characterization and future prospects. In XLIII Congress of Sober. Ribeirão Preto, SP, Brasil

[13] Ravindranath, D. A., \& Radhakrishnan, S. (2016). Coir Pith-Wealth from Waste-A Reference. Published on the Occasion of the India International Coir Fair.

[14] Venugopal, B., \& Sambamurthy, V. (2018). Development and Performance Evaluation of Coir Pith Ash as Supplementary Cementitious Material in Concrete. Journal of Engineering and Technological Sciences, 50(6), 856-869, DOI: $10.5614 \% 2 F j$.eng.technol.sci.2018.50.6.8

[15] 53 Grade Ordinary Portland Cement, IS 12269: 2013, Bureau of Indian Standards, New Delhi, 2013

[16] Bureau of Indian Standards, Guidelines for Concrete Mix Design Proportioning, IS 10262:2009, New Delhi, 2009

[17] Method of Tests for Strength of Concrete, IS 516: 1959, Bureau of Indian Standards, New Delhi, 1959.

[18] Splitting tensile strength of concrete - Method of test, IS 5816: 1999, Bureau of Indian Standards, New Delhi, 1999

[19] Bureau of Indian Standards, Non-destructive Testing of Concrete -Methods of Test, Part 1: Ultrasonic Pulse Velocity, IS 13311 (Part 1), New Delhi, 1999-28,1992 
[20] ASTM C 642-06. Standard Test method for Density, Absorption, and Voids in Hardened Concrete. West Conshohocken, Pennsylvania, United States

[21] ASTM C 267-97. Standard Test Methods for Chemical Resistance of Mortars, Grouts and Monolithic Surfacings and Polymer Concretes. West 128 Conshohocken, Pennsylvania, United States. (Source: http://www.scribd.com/doc/230862 438/C267)

[22] ASTM C 579-01. Standard Test Methods for Compressive Strength of Chemical resistant Mortars, Grouts, Monolithic Surfacings, and Polymer Concretes. West Conshohocken, Pennsylvania, United States. (Source: http://www.scribd.co m/doc/250467834/229667661-ASTM-C-579\#scribd

[23] Hwang, C.L., Bui, L.A.T., \& Chen, C.T. (2011). Effect of rice husk ash on the strength and durability characteristics of concrete. Construction and building materials, 25(9), 3768-3772, DOI: 10.1016/j.conbuildmat.2011.04.009.

[24] Alex, J., Dhanalakshmi, J., \& Ambedkar, B. (2016). Experimental investigation on rice husk ash as cement replacement on concrete production. Construction and Building Materials, 127, 353-362, DOI: 10.1016/j.conbuild mat.2016.09.150

[25] Chusilp, N., Jaturapitakkul, C., \& Kiattikomol, K. (2009). Utilization of bagasse ash as a pozzolanic material in concrete. Construction and Building Materials, 23(11), 3352-3358, DOI: 10.1016/j.conbuildmat.2009.06.030

[26] Ganesan, K., Rajagopal, K., \& Thangavel, K. (2007). Evaluation of bagasse ash as supplementary cementitious material. Cement and concrete composites, 29(6), 515-524, DOI: 10.1016/j.cemconcomp.2007.03.001.

[27] Balagopal, V., \& Sambamurthy, V. (2020). Performance Evaluation of Coir Pith Ash Blended Cement Concrete Exposed to Elevated Temperature. Jurnal Teknologi, 82(2).

[28] Balagopal, V., and Viswanathan T. S. (2020), " Effect of Elevated Temperature on Performance of Concrete Containing Supplementary Cementitious Material Derived from Coir Industry". International Journal of Emerging Trends in Engineering Research, 8(8), 4496 - 4501 